\title{
DONACIINAE (COLEOPTERA: CHRYSOMELIDAE) OF THE REPUBLIC OF MOLDOVA FAUNA
}

\section{Livia Calestru, Victoria Belova}

Institute of Zoology, Chisinau, Republic of Moldova

e-mail: liviacalestru@gmail.com

Abstract. The Donaciinae of the Republic of Moldova (including Transnistria) fauna are reviewed based on collected material, museum collections and available literature data. In total, 14 species of Donaciinae are known from Republic of Moldova.

\section{Introduction}

The leaf beetles (Coleoptera, Chrysomelidae) is one of the largest beetle families and according to some bibliographical sources, from 35 to 50 thousand species are known in the world. Donaciinae is a subfamily of Chrysomelidae and sometimes are called longhorned leaf beetles because of the long antennas comparatively than other chrysomelids. Both the adult and larval stages feed on the same plants and occur in lotic and lentic habitats.

\section{Materials and methods}

The Donaciinae subfamily material presented in the paper includes collections (fig. 1) from the 1924-1939 years stored in the National Museum of Ethnography and Natural History [1] and the recent period (2004-2021) from the Institute of Zoology and available literature data [4-8]. Collecting was performed using standard methods: manual collecting and sweeping with a sweep net. The taxonomic identities of specimens were determined using the key [2].

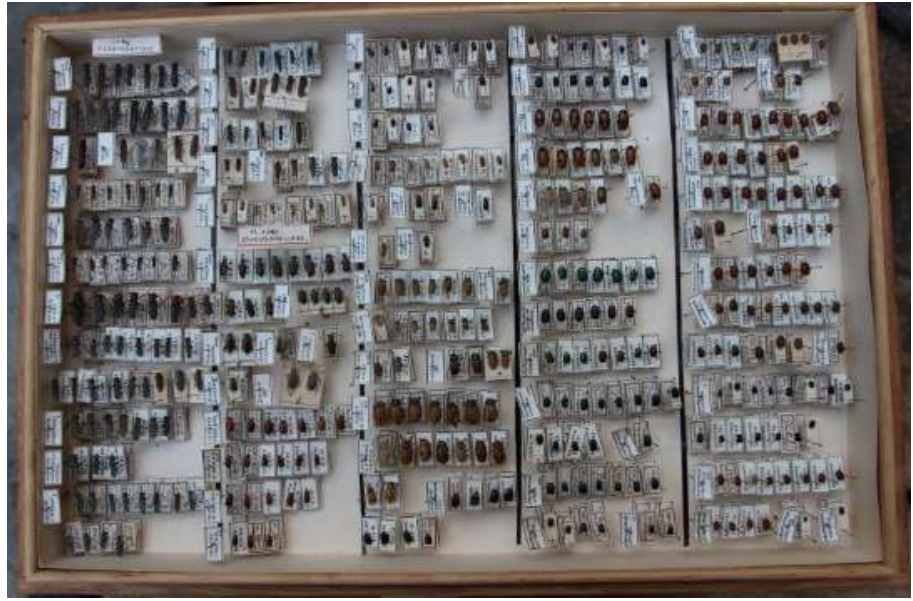

Figure 1. Example of beetles from the National Museum of Ethnography and Natural History collection 


\section{Results and discussion}

In the Republic of Moldova, the following species were identified:

Genus Donacia Fabricius, 1775

Donacia clavipes Fabricius, 1793

General distribution: Europe, Siberia

Distribution in R.Moldova: Chişinău [1], Chişinău [4], "Iagorlîc” Scientific Reserve [5, 6, 7]

Biological data: host plants are Phragmites Adans., Eleocharis R.Br.

\section{Donacia cinerea Herbst, 1784}

General distribution: Europe, Siberia.

Distribution in R.Moldova: Chişinău [4], "Iagorlîc” Scientific Reserve [5, 6, 7]

Biological data: host plants are Typha L., Carex.

Donacia dentata Hoppe, 1795

General distribution: Europe, Middle Asia.

Distribution in R.Moldova: Chişinău [1], Merenesti [7]

Biological data: host plants are Sagittaria sagittifolia and Alisma plantagoaquatica

Donacia brevicornis Ahrens, 1810

General distribution: Europe

Distribution in R.Moldova: Ploti [7], Badragii vechi, 14.07.2016

Biological data: host plants are Scirpus lacustris and Carex L.

Donacia simplex Fabricius, 1775

General distribution: Paleartic region

Distribution in R.Moldova: Goian (Transnistria) [1], Tighina (Bender) [4], "Iagorlîc" Scientific Reserve [7]

Biological data: host plants are Sparganium L., Glyceria L., Carex L.

\section{Donacia polita Kunze, 1818}

General distribution: Northern Africa to South and Eastern Europe.

Distribution in R.Moldova: Chişinău, [4]

Biological data: host plants are Sparganium L., Glyceria L.

Donacia antiqua Kunze, 1818

General distribution: Europe

Distribution in R.Moldova: Chişinău, [1]

Biological data: Carex L.

Donacia bicolora Zschach, 1788

General distribution: Europe.

Distribution in R.Moldova: Chişinău, [4]

Biological data: host plants are Sparganium L., Carex L.

Donacia marginata Hoppe, 1795

General distribution: Northern Africa, Europe, Middle Asia

Distribution in R.Moldova: Chişinău [1] 
Biological data: host plants are Sparganium L. and Carex L.

\section{Donacia semicuprea Panzer, 1796}

General distribution: Northern and Middle Europe

Distribution in R.Moldova: Goian (Transnistria), Chişinău [1]

Biological data: host plants Glyceria aquatica L.

\section{Donacia versicolorea (Brahm, 1790)}

General distribution: Europe

Distribution in R.Moldova: ubiquitous [4]

Biological data: host plants are Typha L., Potamogeton L.

Genus Plateumaris Thomson, 1859

Plateumaris affinis (Kunze, 1818)

General distribution: Europe

Distribution in R.Moldova: r.Orhei, s.Vatici, 20.05.1978 (fig. 2a)

Biological data: host plants are Sparganium L., Carex L.

\section{Plateumaris bracata (Scopoli, 1772)}

General distribution: Spain to Central Asia

Distribution in R.Moldova: Chişinău [4]

Biological data: host plants are Phragmites australis, Eriophorum

\section{Plateumaris sericea (Linnaeus, 1758)}

General distribution: Paleartic region

Distribution in R.Moldova: Goian (Transnistria) [8]; r.Orhei, s.Ivancea, 12.05.1968; (fig. 2b) Rădenii vechi, 19.05.2006; T,aul, 20.06.2004

Biological data: host plants are Carex L., Iris L., Sparganium L.

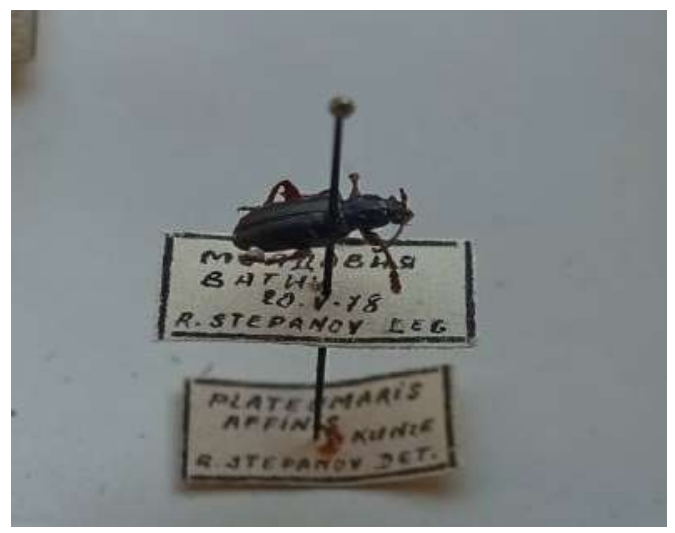

$\mathbf{a}$

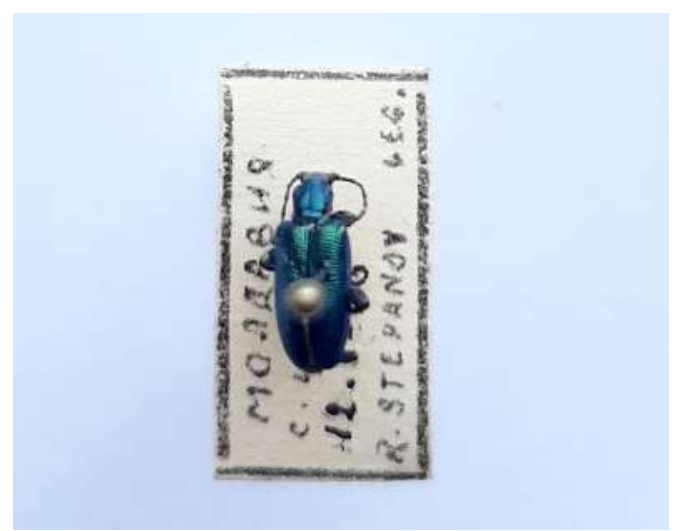

b

Figure 2. Plateumaris affinis (a) and Plateumaris sericea (b)

The study was performed under the project 20.80009.7007.02. 


\section{Bibliography}

1. Derjanschi V., Baban E., Calestru L., Stahi N., Țugulea C. Catalogue of the N. Zubowsky entomological collection. Ch.: "Bons Offices", 2016, 296 p.

2. Беньковский A.О. Определитель жуков-листоедов (Coleoptera, Chrysomelidae) Европейской части России и европейских стран ближнего зарубежья. Москва, 1999, 204 c.

3. Лопатин И.К. Жуки-листоеды фауны Белорусии и Прибалтики: Определитель. Минск, 1986, $129 \mathrm{c}$.

4. Медведев С.И., Шапиро Д.С. К познанию фауны жуков (Coleoptera) Молдавской ССР и сопредельных районов Украины. Тр. НИИ биологии и биол. факульт. Харьковского Гос. Унив., Т. 30. Харьков, 1957, с.173-206.

5. Мосейко А.Г., Котомина Л.В. Некоторые сведения о жуках-листоедах (Coleoptera, Chrysomelidae) заповедника “Ягорлык”. Проблемы сохранения биоразнообразия Днестра. Кишинев, 1999, с. 155-158.

6. Мосейко А.Г. К познанию фауны жуков-листоедов (Coleoptera, Chrysomelidae) заповедника “Ягорлык”. Заповедник “Ягорлык”. Eco-TIRAS, Тирасполь, 2006. С. 145146.

7. Мосейко А.Г. Жуки-листоеды (Coleoptera, Chrysomelidae) Приднестровья. Чтения памяти кандидата биологических наук, доцента Л.Л. Попа. Тирасполь: ПГУ им. Т.Г. Шевченко, 2015, с. 36-73.

8. Мосейко А.Г. Новые и интересные находки жуков-листоедов (Coleoptera, Chrysomelidae) в Приднестровье. Есо-TIRAS, Тирасполь, 2018, с. 155-156. 